\title{
EFFECT OF COLLOID VS CRYSTALLOID PRELOAD ON HEMODYNAMIC STABILITY IN ELDERLY PATIENTS UNDERGOING LOWER LIMB ORTHOPEDIC SURGERY UNDER SPINAL ANESTHESIA
}

By

\section{Ahmed Sultan**, Hassanin Abd Al-Karem*, Ahmed Said* and Ahmed M. El-Garhy*}

*Department of Anesthesia and Intensive Care, Faculty of Medicine, Al Azhar University

***Department of Anesthesia, Nasser Institute Hospital

Financial support: No financial support

Conflicts of interest: There are no conflicts of interest

Running title: Colloid VS Crystalloid in spinal anesthesia

Corresponding author: Ahmed Sultan, E-mail: dr.sultan14@gmail.com

Mobile: 01064488532, Postal Code: 15643

\begin{abstract}
Background: Hypotension is commonly occurred with Spinal anesthesia. Colloids and Crystalloids are used preoperatively to prevent hypotension.

Objective: To examine the effect of fluid (crystalloid vs. colloid) preloading on hemodynamic stability in old patients planned for lower limb orthopedic operations with spinal anesthesia.

Patients and methods: Eighty patients undergoing orthopedic surgery under spinal anesthesia were included in this work. Their age ranged between 60-80 years. Patients were allocated randomly to either Crystalloid (Ringer solution RS group) or Colloid (hydroxyethyl starch solution HES group). Intravenous preload of 10 $\mathrm{mL} / \mathrm{kg}$ of either lactated Ringer's solution in the RS group or hydroxyethyl starch solution (6\% HES 130/0.4; Voluven) in the HES group was infused over 20 min before spinal anesthesia.. Hemodynamic parameters were recorded, and all results were compared.
\end{abstract}

Results: More than 20\% drop in systolic blood pressure occurred in $45 \%$ patients in the crystalloid group compared to $15 \%$ patients in the colloid group. This difference was significant statistically $(\mathrm{p}<0.01)$. Regarding requirement of ephedrine to treat hypotension, (45\% of patients in crystalloid group required Ephedrine compared to $15 \%$ patients in colloid group). This was also statistically significant $(\mathrm{p}<0.01)$.

Conclusion: Colloid solution was better than crystalloid solution in controlling blood pressure, ephedrine requirements and heart rate changes.

Key words: Colloid; preload; elderly; spinal anesthesia. 


\section{INTRODUCTION}

Spinal anesthesia is the preferred choice for surgery of lower limb, cause of being simple and no need for support of airway (Memtsoudis et al., 2013).

Hypotension is commonly occurred with spinal anesthesia. The mechanism of this hypotension is spinal nerve block, peripheral arterial vasodilation, lower venous return, and decrease of the cardiac output (Bishop et al., 2017).

Volume preloading is an effective method to prevent hypotension caused by spinal anesthesia. Various crystalloids and colloids solutions have been used as preloading fluid for prevention of hypotension (Mandal et al., 2016).

This study aimed to compare crystalloid and colloid preload on hemodynamic stability in old age patients planned for lower limb orthopedic operations under spinal anesthesia.

\section{PATIENTS AND METHODS}

This prospective randomized, singleblind clinical study was conducted at Nasser Institute Hospital, Cairo, Egypt, between June 2019 and November 2019, after getting approval from the hospital ethical committee.

Informed written consents were obtained from eighty patients who were planned for elective orthopedic surgery under spinal anasethesia.

Inclusion criteria: Patients belonged to American Society of Anesthesiologists physical status I, II, age group between 60 and 80 years.

Exclusion criteria: Patients refused to participate, patients of congestive heart failure, unstable angina, significant valve disease, recent myocardial infarction, severe arrhythmia, renal diseases, other contraindications to spinal anesthesia and who suffered from intraoperative massive blood loss.

Patients were classified equally by computer-generated random number and sealed opaque envelopes into two groups: The crystalloid (Ringer solution -RS) group, and colloid (hydroxyethyl starch solution- HES) group.

Ten $\mathrm{mL}$ per $\mathrm{kg}$ of Ringer's lactate (Otsuka Ateco pharma Egypt) in the crystalloid group or hydroxyethyl starch solution (6\% Voluven) in the colloid group was administered over 20 mins before spinal anesthesia. Thereafter, all patients were maintained on intravenous ringer's lactate solution as maintenance at approximately $2 \mathrm{~mL} / \mathrm{kg}$ per hour in addition to replacement of blood loss.

Once intravenous fluid preloading was finished, spinal anesthesia was done at the intervertebral space L3-L4 or L4-L5 using a 27-gauge pencil-point needle (Galena Medical Corporation) with the patient placed sitting. After free flow of the CSF, $3 \mathrm{~mL}$ hyperbaric $0.5 \%$ bupivacaine plus $20 \mathrm{mcg}$ of fentanyl were intrathecally injected over 10 seconds, and the patient was turned supine after that. Blood pressure, oxygen saturation, heart rate were recorded immediately after preload, immediately after spinal anesthesia, every 5 minutes in the first 30 minutes and then every 15 minutes. \% Change was calculated in all parameters. Data were expressed as mean \pm standard deviation.

Hypotension is treated with an ephedrine bolus (2.5-10 $\mathrm{mg}$ ), repeated as 
needed every 3 to 4 minutes, and bradycardia treated with intravenous atropine $(0.1 \mathrm{mg} / \mathrm{kg})$.

The primary outcome of our study was to measure blood pressure. Heart rate and $\mathrm{SpO} 2$ were measured as secondary outcomes. This method was to study the effect of fluid preload whether colloid or crystalloid in hemodynamic stability, other hemodynamic changes, and total requirement of vasopressor during operation.

Ethical Considerations: Permission was obtained from the Department of Anesthesia at Nasser Institute, and then by the ethical committee of Al-Azhar University. An informed verbal consent from every participant was taken and confidentiality of information was assured.

Statistical analysis: Calculation of sample size was based on similar literature. We calculated that a sample of 40 patients in each group was sufficient to give $\alpha=0.05$ with confidence interval $95 \%$ and actual power $90 \%$.
Statistical Package for Social Science was used (IBM Corp. Released 2015) version 15 . The Inter group quantitative data were written in the form of mean, standard deviations, and ranges when parametric, median with inter-quartile range (IQR) when nonparametric and numbers with percentages for qualitative data. Two groups comparison was done by using Independent t-test (regarding quantitative data with parametric distribution) and with Mann-Whitney test (non-parametric distribution), while the comparison between two groups regarding categorical data were done by using Chisquare test. A one-way analysis of variance (ANOVA) was used when comparing between more than two means, followed by post hoc test. The Intra group data were done using Dunnett test. The confidence interval was set to $95 \%$ and the margin of error accepted was set to $5 \%$. So, the p-value was considered significant at $\mathrm{p} \leq 0.05$.

\section{RESULTS}

The present study was a single-blind randomized comparative study to examine the effect of colloid and crystalloid preload on hemodynamic stability in elderly patients undergoing lower limb orthopedic operations under spinal anesthesia.

As regards Demographic data (age, sex, height, and weight), there was no significant difference between the two studied groups (Table 1).

Table (1): Comparison between studied groups regarding demographic data (mean \pm SD)

\begin{tabular}{|c|c|c|c|c|c|c|}
\hline \multicolumn{2}{|c|}{$\begin{array}{cc}\text { Parameters } & \text { Groups } \\
\end{array}$} & \multicolumn{2}{|c|}{$\begin{array}{l}\text { Crystalloid Group } \\
(\mathrm{N}=40)\end{array}$} & \multicolumn{2}{|c|}{$\begin{array}{c}\text { Colloid Group } \\
\mathrm{N}=40\end{array}$} & P-Value \\
\hline \multicolumn{2}{|c|}{ Age (Years) } & \multicolumn{2}{|c|}{$68 \pm 9.9$} & \multicolumn{2}{|c|}{$70 \pm 11.8$} & 0.48 \\
\hline \multirow{2}{*}{$\operatorname{sex}$} & Male & & $60 \%$ & 22 & $55 \%$ & \multirow{2}{*}{0.65} \\
\hline & Female & 16 & $40 \%$ & 18 & $45 \%$ & \\
\hline \multicolumn{2}{|c|}{ Height $(\mathrm{Cm})$} & \multicolumn{2}{|c|}{$166.4 \pm 9.4$} & \multicolumn{2}{|c|}{$164.7 \pm 11.4$} & 0.46 \\
\hline \multicolumn{2}{|c|}{ Weight (Kg) } & \multicolumn{2}{|c|}{$74.5 \pm 4.7$} & \multicolumn{2}{|c|}{$72.9 \pm 6.4$} & 0.206 \\
\hline
\end{tabular}


SBP and DBP showed significant difference between groups at 10 and 15 min, whereas no statistical significant difference ( $p$-value > 0.05) between the groups after preloading, immediately after anesthesia , and 5, 20, 25, 30, 45, 60, 75, 90, $105 \& 120$ min after anesthesia (Table 2).

Table (2): Comparison of SBP and DBP in both groups at different intraoperative time intervals

\begin{tabular}{|c|c|c|c|c|c|c|}
\hline \multicolumn{2}{|c|}{ Time (min) } & $\begin{array}{l}\text { Crystalloid } \\
(\mathrm{N}=40)\end{array}$ & $\%$ Change & $\begin{array}{l}\text { Colloid } \\
(\mathrm{N}=40)\end{array}$ & $\begin{array}{c}\% \\
\text { Change }\end{array}$ & $\begin{array}{c}\mathrm{P}- \\
\text { value }\end{array}$ \\
\hline \multicolumn{7}{|c|}{ SBP } \\
\hline \multicolumn{2}{|c|}{ [Baseline]) } & $127.1 \pm 5.4$ & $\begin{array}{ll}--- \\
\end{array}$ & $125.1 \pm 8.4$ & $\begin{array}{ll}--- \\
\end{array}$ & 0.2 \\
\hline \multicolumn{2}{|c|}{$\begin{array}{c}\text { Immediately after } \\
\text { anesthesia }\end{array}$} & $124.7 \pm 5.6$ & 1.9 & $123.9 \pm 8.6$ & 0.96 & 0.62 \\
\hline \multicolumn{2}{|c|}{5 After anesthesia } & $115.3 \pm 8.3$ & 9.3 & $116.1 \pm 6.5$ & 7.2 & 0.63 \\
\hline \multicolumn{2}{|c|}{10} & $104.1 \pm 12.4$ & 18 & $111.8 \pm 9.7$ & 10.6 & 0.003 \\
\hline \multicolumn{2}{|c|}{15} & $101.1 \pm 11.8$ & 20.5 & $107.7 \pm 8.5$ & 13.9 & 0.005 \\
\hline \multicolumn{2}{|c|}{20} & $101.08 \pm 14.5$ & 20.5 & $104.2 \pm 12.6$ & 16.7 & 0.3 \\
\hline \multicolumn{2}{|c|}{25} & $104.1 \pm 7.8$ & 18 & $104.8 \pm 10.9$ & 16.2 & 0.74 \\
\hline \multicolumn{2}{|c|}{30} & $105.5 \pm 8.9$ & 17 & $106.1 \pm 7.9$ & 15.2 & 0.75 \\
\hline \multicolumn{2}{|c|}{45} & $106.2 \pm 6.6$ & 16.4 & $108.5 \pm 9.5$ & 13.3 & 0.21 \\
\hline \multicolumn{2}{|c|}{60} & $106.5 \pm 8.4$ & 16.2 & $109.2 \pm 10.5$ & 12.7 & 0.2 \\
\hline \multicolumn{2}{|c|}{75} & $106.9 \pm 13.6$ & 15.9 & $110.4 \pm 11.2$ & 11.8 & 0.21 \\
\hline \multicolumn{2}{|c|}{90} & $108.5 \pm 12.7$ & 14.6 & $112.9 \pm 13.2$ & 9.8 & 0.13 \\
\hline \multicolumn{2}{|c|}{105} & $108.9 \pm 11.6$ & 14.3 & $113.2 \pm 10.4$ & 9.5 & 0.08 \\
\hline \multicolumn{2}{|c|}{120} & $109.9 \pm 13.5$ & 13.5 & $114.7 \pm 12.5$ & 8.3 & 0.09 \\
\hline \multirow[b]{2}{*}{ ANOVA } & $\mathrm{F}$ & 43.8 & & 47.4 & & \\
\hline & $\begin{array}{c}\mathrm{p}- \\
\text { value }\end{array}$ & $<0.001 *$ & & $<0.001 *$ & & \\
\hline \multicolumn{7}{|l|}{ DBP } \\
\hline \multicolumn{2}{|c|}{ [Baseline]) } & $78.2 \pm 7.5$ & ------ & $78.4 \pm 5.5$ & ------ & 0.89 \\
\hline \multicolumn{2}{|c|}{$\begin{array}{c}\text { Immediately after } \\
\text { anesthesia }\end{array}$} & $76.8 \pm 7.5$ & 1.8 & $78.3 \pm 4.5$ & 0.01 & 0.22 \\
\hline \multicolumn{2}{|c|}{5 After anesthesia } & $72.9 \pm 7.9$ & 6.8 & $75.4 \pm 5.3$ & 3.8 & 0.1 \\
\hline \multicolumn{2}{|c|}{10} & $69.3 \pm 7.3$ & 11.4 & $73.2 \pm 7.8$ & 6.6 & 0.023 \\
\hline \multicolumn{2}{|c|}{15} & $67.3 \pm 8.9$ & 14 & $71.9 \pm 10.7$ & 8.3 & 0.039 \\
\hline \multicolumn{2}{|c|}{20} & $65.7 \pm 6.9$ & 16 & $70.7 \pm 8.5$ & 9.8 & 0.005 \\
\hline \multicolumn{2}{|c|}{25} & $67.4 \pm 9.7$ & 13.8 & $70.8 \pm 9.6$ & 9.7 & 0.11 \\
\hline \multicolumn{2}{|c|}{30} & $69.5 \pm 7.8$ & 11.1 & $71.3 \pm 10.7$ & 9.1 & 0.39 \\
\hline \multicolumn{2}{|c|}{45} & $68.8 \pm 11.5$ & 12 & $71.6 \pm 9.8$ & 8.7 & 0.24 \\
\hline \multicolumn{2}{|c|}{60} & $70.1 \pm 9.5$ & 10.4 & $72.3 \pm 7.9$ & 7.8 & 0.26 \\
\hline 7 & & $70.5 \pm 10.7$ & 9.8 & $73.7 \pm 7.4$ & 6 & 0.12 \\
\hline 9 & & $71.7 \pm 9.9$ & 8.3 & $73.9 \pm 5.7$ & 5.7 & 0.22 \\
\hline 10 & & $72.2 \pm 8.4$ & 7.7 & $74.4 \pm 8.9$ & 5.1 & 0.25 \\
\hline 12 & & $72.8 \pm 8.3$ & 6.9 & $75.3 \pm 7.9$ & 4 & 0.17 \\
\hline & $\mathrm{F}$ & 51.4 & & 58.3 & & \\
\hline ANOVA & $\begin{array}{c}\mathrm{p}- \\
\text { value }\end{array}$ & $<0.001 *$ & & $<0.001 *$ & & \\
\hline
\end{tabular}

Statistically significant difference in the number of patients developed fall in systolic and diastolic blood pressure > $20 \%$ of the base line (Table 3). 
Table (3): Fall in SBP and DBP from the baseline

\begin{tabular}{|c|c|c|c|c|c|c|}
\hline Groups & $\%$ fall & \multicolumn{2}{|c|}{$\begin{array}{c}\text { Crystalloid } \\
(\mathrm{N}=40)\end{array}$} & \multicolumn{2}{|c|}{$\begin{array}{c}\text { Colloid } \\
(\mathrm{N}=40)\end{array}$} & \multirow{2}{*}{ P-value } \\
\hline \multirow{2}{*}{ Systolic } & $<20 \%$ & 22 & $55 \%$ & 34 & $85 \%$ & \multirow{2}{*}{$0.003 * *$} \\
\cline { 2 - 7 } & $>20 \%$ & 18 & $45 \%$ & 6 & $15 \%$ & \\
\hline \multirow{2}{*}{ Diastolic } & $<20 \%$ & 24 & $60 \%$ & 35 & $87.5 \%$ & \multirow{2}{*}{$0.005 * *$} \\
\cline { 2 - 6 } & $>20 \%$ & 16 & $40 \%$ & 5 & $12.5 \%$ & \\
\hline
\end{tabular}

Regarding HR, there was statistically significant difference (p-value $<0.05$ ) between the studied groups at 10 and 15 min, whereas no statistical significant difference ( $p$-value > 0.05) between the groups after preloading, immediately after anesthesia, 5, 20, 25, 30, 45, 60, 75, 90, 105 , and $120 \mathrm{~min}$. Regarding $\mathrm{SpO} 2$, no statistically significant difference ( $p$-value $>0.05)$ is observed between Crystalloid and Colloid groups (Table 4).

Table (4): Comparison of H.R and $\mathrm{SPO}_{2}$ in both groups at different intraoperative time intervals

\begin{tabular}{|c|c|c|c|c|c|c|}
\hline \multicolumn{2}{|c|}{$\begin{array}{ll}\text { Time (min) } & \text { Groups }\end{array}$} & $\begin{array}{l}\text { Crystalloid } \\
(\mathrm{N}=40)\end{array}$ & $\%$ Change & $\begin{array}{l}\text { Colloid } \\
(\mathrm{N}=40)\end{array}$ & $\%$ Change & P-value \\
\hline \multicolumn{7}{|l|}{ Heart rate } \\
\hline \multicolumn{2}{|c|}{ After pre-load } & $77 \pm 4.9$ & & $75 \pm 4.3$ & & 0.56 \\
\hline \multicolumn{2}{|c|}{ Immediately after anesthesia } & $80 \pm 4.3$ & 3.9 & $79 \pm 4.8$ & 5.3 & 0.43 \\
\hline \multicolumn{2}{|c|}{5} & $85 \pm 5.1 *$ & 10.4 & $83 \pm 4.7$ & 10.7 & 0.92 \\
\hline \multicolumn{2}{|c|}{10} & $93 \pm 4.3^{*}$ & 20.8 & $87 \pm 2.7$ & 16 & 0.001 \\
\hline \multicolumn{2}{|c|}{15} & $97 \pm 6.3 *$ & 26 & $92 \pm 3.6$ & 22.7 & 0.001 \\
\hline \multicolumn{2}{|c|}{20} & $88 \pm 4.7 *$ & 14.3 & $86 \pm 4.9$ & 14.7 & 0.85 \\
\hline \multicolumn{2}{|c|}{25} & $86 \pm 5.8 *$ & 11.7 & $84 \pm 4.8$ & 12 & 0.5 \\
\hline \multicolumn{2}{|c|}{30} & $85 \pm 5.3^{*}$ & 10.4 & $83 \pm 5.1$ & 10.7 & 0.49 \\
\hline \multicolumn{2}{|c|}{45} & $80 \pm 5.2 *$ & 3.9 & $81 \pm 5.5$ & 8 & 0.36 \\
\hline \multicolumn{2}{|c|}{60} & $81 \pm 6.3^{*}$ & 5.2 & $82 \pm 5.7$ & 9.3 & 0.55 \\
\hline \multicolumn{2}{|c|}{75} & $83 \pm 4.3^{*}$ & 7.8 & $85 \pm 5.1$ & 13.3 & 0.63 \\
\hline \multicolumn{2}{|c|}{90} & $85 \pm 5.2^{*}$ & 10.4 & $84 \pm 4.8$ & 12 & 0.37 \\
\hline \multicolumn{2}{|c|}{105} & $83.1 \pm 3.7 *$ & 7.9 & $84.1 \pm 4.5$ & 12.1 & 0.28 \\
\hline \multicolumn{2}{|c|}{120} & $83.0 \pm 4.3^{*}$ & 7.8 & $83.9 \pm 4.7$ & 11.9 & 0.37 \\
\hline \multirow{2}{*}{ ANOVA } & $\mathrm{F}$ & 48.6 & & 52.7 & & \\
\hline & p-value & $<0.001^{*}$ & & $<0.001 *$ & & \\
\hline \multicolumn{7}{|l|}{$\mathrm{SPO}_{2}$} \\
\hline \multicolumn{2}{|c|}{ After pre-load } & \multicolumn{2}{|c|}{$97.3 \pm 2.3$} & \multicolumn{2}{|c|}{$97.2 \pm 2.4$} & 0.84 \\
\hline \multicolumn{2}{|c|}{ Immediately after anesthesia } & \multicolumn{2}{|c|}{$97.5 \pm 2.4$} & \multicolumn{2}{|c|}{$97.3 \pm 2.5$} & 0.71 \\
\hline \multicolumn{2}{|c|}{10} & \multicolumn{2}{|c|}{$97.8 \pm 2.1$} & \multicolumn{2}{|c|}{$97.5 \pm 2.6$} & 0.57 \\
\hline \multicolumn{2}{|c|}{15} & \multicolumn{2}{|c|}{$97.9 \pm 2.3$} & \multicolumn{2}{|c|}{$97.7 \pm 2.5$} & 0.71 \\
\hline & & 98.1 & 2.5 & 97.9 & 2.6 & 0.72 \\
\hline & & 98.2 & 2.4 & 97.5 & 2.2 & 0.56 \\
\hline & & 98.1 & 2.3 & 98.0 & 2.5 & 0.85 \\
\hline & & 98.3 & 2.6 & 98.2 & 2.6 & 0.86 \\
\hline & & 98.3 & 2.5 & 98.2 & 2.4 & 0.86 \\
\hline & & 98.4 & 2.5 & 98.3 & 2.4 & 0.86 \\
\hline & & 98.5 & 2.4 & 98.3 & 2.3 & 0.7 \\
\hline & & 98.4 & 2.3 & 98.2 & 2.5 & 0.71 \\
\hline & & 98.4 & 2.5 & 98.3 & 2.4 & 0.85 \\
\hline
\end{tabular}


Regarding requirement of Ephedrine for treatment of hypotension, there was a statistically significant difference ( $p$-value $<0.05$ ) between studied groups $45 \%$ of patients in crystalloid group, and $15 \%$ of patients in colloid. Regarding Total dose of Ephedrine given for treatment of hypotension, there is statistically significant difference ( $\mathrm{p}$-value $<0.05$ ) between studied groups, crystalloid group need more dose of ephedrine than colloid group group (Table 5).

Table (5): Requirement of Ephedrine in treating hypotension in both groups

\begin{tabular}{|c|c|c|c|c|c|c|c|}
\hline \multirow{2}{*}{ Groups } & \multicolumn{2}{c|}{$\begin{array}{c}\text { Crystalloid } \\
\text { Parameters }\end{array}$} & \multicolumn{2}{c|}{$\begin{array}{c}\text { Colloid } \\
(\mathrm{N}=40)\end{array}$} & \multicolumn{2}{c|}{ Chi-square } \\
\cline { 5 - 7 } \cline { 5 - 6 } Ephedrine & Yes & 18 & $45 \%$ & 6 & $15 \%$ & \multirow{2}{*}{8.5} & \multirow{2}{*}{0.003} \\
\cline { 3 - 6 } & No & 22 & $55 \%$ & 34 & $85 \%$ & & \\
\hline
\end{tabular}

\begin{tabular}{|c|c|c|c|}
\hline Total dose of & & \\
Ephedrine Given & 14.0 & 7.0 & 0.001 \\
$(\mathrm{mg})$ & $(4.0-21.0)$ & $(2.0-14.0)$ & \\
Median (1st-3rd IQ) & & & \\
\hline
\end{tabular}

As regards adverse effects, there was a statistically significant decrease in numbers of patients developed nausea and vomiting in colloid group. Allergic reaction was observed in only one case in colloid group. Other adverse effects as nausea was observed in 4 patients in colloid group compared to 15 patients in the crystalloid group. Regarding vomiting,
6 patients in the crystalloid group suffered vomiting, while in the colloid group only one case suffered vomiting. Regarding allergic reactions, there was no statistically significant difference between both groups in accordance to allergy. No patients developed hypoxia in both groups (Table 6).

Table (6): Comparison of adverse effects between both studied groups (Number of patients): Chi-square test

\begin{tabular}{|c|c|c|c|}
\hline Groups & $\begin{array}{c}\text { Crystalloid Group } \\
(\mathrm{N}=40)\end{array}$ & $\begin{array}{c}\text { Colloid Group } \\
\mathrm{N}=40\end{array}$ & P-Value \\
\hline Adverse effects & 0 & 1 & 0.312 \\
\hline Nausea & 15 & 4 & 0.001 \\
\hline Vomiting & 6 & 1 & 0.041 \\
\hline Hypoxia & 0 & 0 & \\
\hline
\end{tabular}

\section{DISCUSSION}

In our study, we recorded vital parameters immediately after preload, immediately after spinal anesthesia and every five minutes throughout the first 30 minutes because there is high probability of hypotension within this period, and then every 15 minutes. There was fall in SBP and DBP in both groups. The fall in
SBP in both groups was significant. The values of SBP were significantly less in crystalloid group during 5 to 20 min than colloid group.

Our findings agreed with a study done by Gousheh et al. (2018) who concluded that the decreases in systolic and diastolic blood pressure in the colloid group were less than those of the crystalloid group 
with statistically significant differences. Also, Mandal et al. (2016) concluded that the preloading with hydroxyethyl starch $(6 \%)$ in elective ciesarean section could prevent maternal hypotension more than Ringer solution with fewer side effects.

Ripolles et al. (2015) observed that a significant reduction in hypotension incidence with the use of colloids compared to crystalloids. Upadya et al. (2016) concluded that the incidence of hypotension was lower in the colloid group than in the crystalloid group.

In contrast to the current study, A study done by Fathi et al. (2013) on patients with femoral fracture surgeries showed that colloid was not significantly better in compensation of hypotension caused by spinal anesthesia, also Buggy et al. (2013) showed a high rate of hypotension after spinal anesthesia in elderly patients undergoing elective surgeries occurred regardless of whether crystalloid, colloid, or no prehydration was used. This could be due to difference in age groups or dose used.

Our study showed tachycardia in both groups which was significant. Values of HR were significantly more in crystalloid group during 5 to $20 \mathrm{~min}$ than colloid group.

A study done by Gousheh et al. (2018) has studied the effect of prespinal anesthesia of colloid and crystalloid solutions on incidence of hypotension and HR changes. They found that incidence of tachycardia was lower in the colloid than the crystalloid group. These results agree with our findings. However, the results of the study done by Alimian et al. (2014) was inconsistent with our results, as they found that no significant difference in HR changes between the crystalloid group and colloid group.

We found that both groups required ephedrine to treat hypotension, but there was statistically significant difference between the groups. Requirement of ephedrine was fewer in colloid group than in the crystalloid group. $45 \%$ of the patients in the crystalloid group required ephedrine for treatment of hypotension, while it was only $15 \%$ in the colloid group. This finding was consistent with the study done by Gousheh et al. (2018) who found that average quantity of ephedrine was significantly higher in the crystalloid group than colloid group. Upadya et al. (2016) showed that requirements of ephedrine were significantly higher in patients who had crystalloid than colloid prior to elective cesarean section.

Buggy et al. (2013) found that the average quantity of ephedrine was similar, regardless of prehydration.

Regarding adverse effects, allergic reaction was observed in only one case in colloid group. No patients developed hypoxia in both groups. Other side effects such as nausea and vomiting were observed in some patients but less in patients of the colloid group than in those of the crystalloid group.

\section{CONCLUSION}

Colloid solution has better performance than the crystalloid solution in controlling blood pressure and adjusting other hemodynamic changes with minimal side effects.

Conflicts of interest: No conflicts of interest were found. 


\section{AHMED SULTAN et al.,}

\section{REFERENCES}

1. Alimian M, Mohseni M, Safaeian R, Faiz SH and Majedi MA (2014): Comparison of hydroxyethyl starch $6 \%$ and crystalloids for preloading in elective caesarean section under spinal anesthesia. Med Arch, 68(4):279-281.

2. Bishop DG, Cairns C, Grobbelaar $M$ and Rodseth RN (2017): Heart rate variability as a predictor of hypotension following spinal for elective caesarean section: a prospective observational study. Anaesthesia, 72(5):603608.

3. Buggy D, Higgins $P$, Ciaran $M$ and Maire $M$ (2013): Prevention of spinal anesthesiainduced hypotension in the elderly: comparison between preanesthetic administration of crystalloids, colloids, and no prehydration. Anesthesia and Analgesia, 84 (1) : 106-110.

4. Fathi M, Imani F, Joudi $M$ and Goodarzi V (2013): Comparison between the effects of Ringer`s lactate and hydroxyethyl starch on hemodynamic parameters after spinal anesthesia: A randomized clinical trial. Anesth Pain Med.; 2(3):127-133.

5. Madhusudan U, Bhat $\mathbf{S}$ and Paul $\mathbf{S}$ (2016): Six percent hetastarch versus lactated Ringer's solution - for preloading before spinal anesthesia for cesarean section. Anesth Essays Res 2016; 10:33-37.

6. Mehdi F, Farnad I, Marjan J and Vahid G (2013): Comparison Between the Effects of Ringer`s Lactate and Hydroxyethyl Starch on Hemodynamic Parameters After Spinal Anesthesia: A Randomized Clinical Trial. Anesth Pain Med; 2(3): 127-133.
7. Memtsoudis S, Sun X, Chiu Y, Stundner O, Liu S, Banerjee $S$, Mazumdar $M$ and Sharrock N (2013): Perioperative comparative effectiveness of anesthetic technique in orthopedic patients. Anesthesiology 2013; 118: 1046-1058.

8. Mohammad G, Reza A, Hamid A, Alireza O and Mahbobe R (2018): The Effects of PreSpinal Anesthesia Administration of Crystalloid and Colloid Solutions on Hypotension in Elective Cesarean Section. Anesthesiology and pain medicine vol. 8,4 e69446.

9. Mohanchandra M, Subhrajyoti C, Teesta B and Sumit C (2016): Comparison of crystalloid and colloid preload on maternal hemodynamics in elective caesarean section under spinal anaesthesia. Int J Res Med Sci; 4(6):2428-2435.

10. Ripolles M, Espinosa A, Martinez E, Casans R, Navarro R and Abad A (2015): Colloids versus crystalloids in the prevention of hypotension induced by spinal anesthesia in elective cesarean section. A systematic review and meta-analysis. Minerva Anestesiol., 81(9):1019-1030.

11. Tawfik M, Hayes S, Jacoub F, Badran B, Gohar F, Shabana A, Abdelkhalek $M$ and Emara M (2014): Comparison between colloid preload and crystalloid co-load in cesarean section under spinal anesthesia: a randomized controlled trial.Int J Obstet Anesth, 23(4):317-323. 


\section{مقارنة بين تأثنير التحميل المسبق بالمحاليل الغروية و}

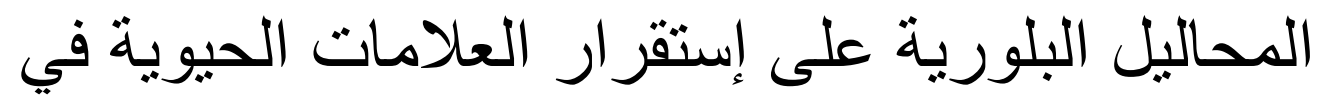

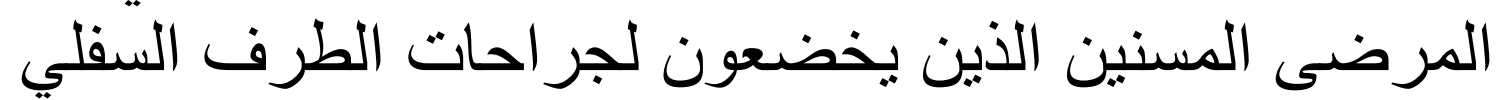
تحت ثأثثر التخدير النخاعي

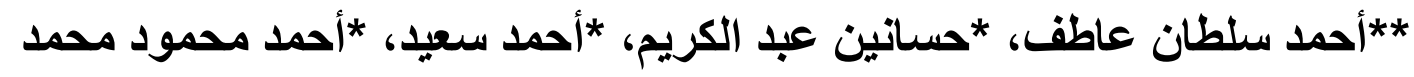

$$
\text { الجارحي }
$$

* قسم التخلير والغناية المركزة بكلية الطب جامعة الأزهر

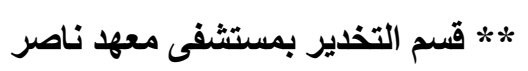

E-mail: dr.sultan14@gmail.com

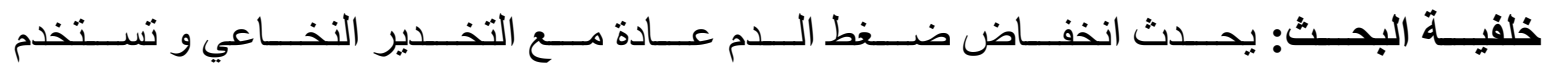
الحاليل الغروية والبلورية قبل الجر احة لنع انخفاض ضغط الدم.

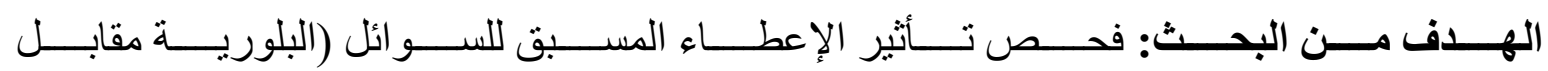

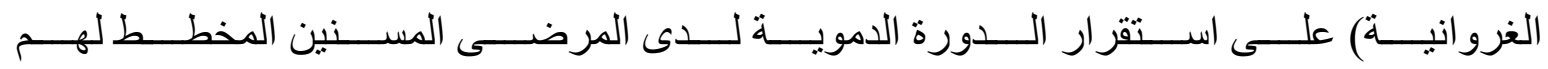
لعمليات تقويم الأطراف السفلية باستخدام التخدير النخاعي.

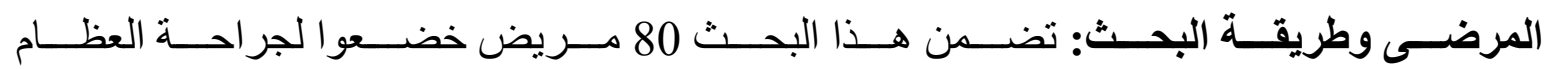

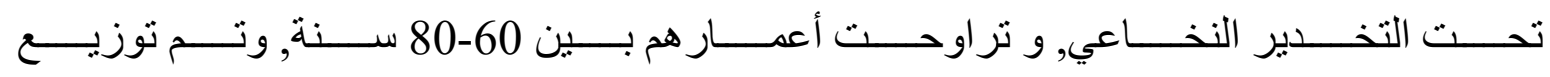

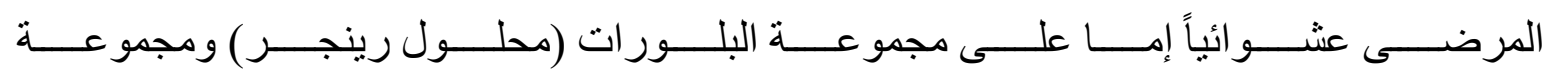

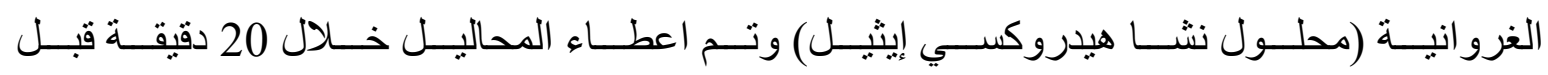

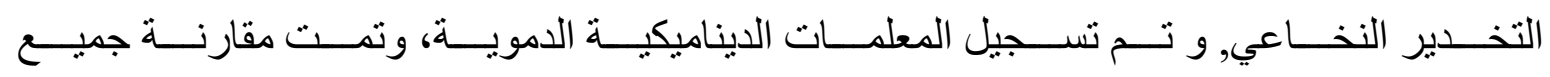
النتائج.

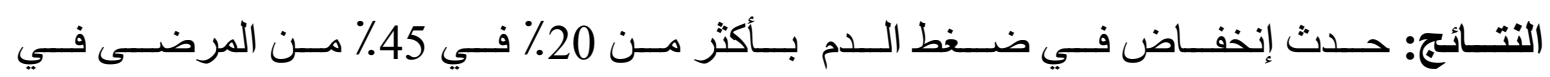

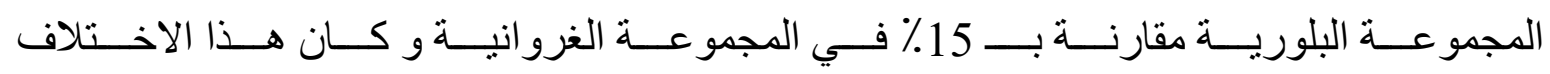

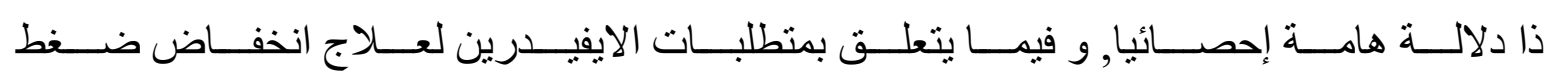

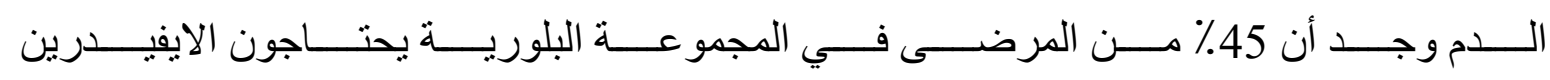
مقارنة مع 15٪ من المرضى في المجمو عة الغروانية. 


\section{AHMED SULTAN et al.,}

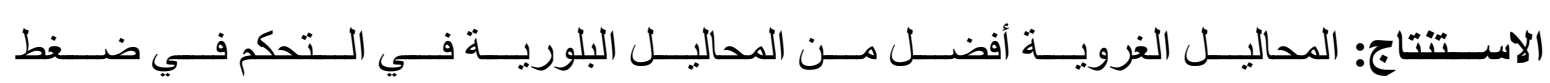
الدم ومنطلبات الايفيدرين وتغير ات معدل ضربات القلب.

الكلمات الدالة: التخدير النخاعي, المحاليل البلورية, المحاليل الغرو انية. 